January 2022

\title{
Introducing the Remote Mentoring of Undergraduate Research Students (ReMentURS) Workshop Series: Initial Evaluation and Plans for Wider Implementation
}

\author{
Elizabeth Sargent \\ Georgia Southern University, College of Science and Mathematics, esargent@georgiasouthern.edu \\ Abid Shaikh \\ Georgia Southern University; Department of Chemistry and BioChemistry, malnu@georgiasouthern.edu \\ Karla Sue Marriott \\ Savannah State University; Roger Williams University, kmarriott@rwu.edu \\ Taysia Porter \\ Georgia Southern University; Department of Chemistry and BioChemistry, tp11487@georgiasouthern.edu \\ Dawn N. Cannon-Rech \\ Georgia Southern University, dcannonrech@georgiasouthern.edu
}

See next page for additional authors

Follow this and additional works at: https://digitalcommons.georgiasouthern.edu/ij-sotl

\section{Recommended Citation}

Sargent, Elizabeth; Shaikh, Abid; Marriott, Karla Sue; Porter, Taysia; Cannon-Rech, Dawn N.; and Landge, Shainaz M. (2022) "Introducing the Remote Mentoring of Undergraduate Research Students (ReMentURS) Workshop Series: Initial Evaluation and Plans for Wider Implementation," International Journal for the Scholarship of Teaching and Learning: Vol. 16: No. 1, Article 7.

Available at: https://doi.org/10.20429/ijsotl.2022.160107 


\title{
Introducing the Remote Mentoring of Undergraduate Research Students (ReMentURS) Workshop Series: Initial Evaluation and Plans for Wider Implementation
}

\begin{abstract}
The primary objective of the Remote Mentoring of Undergraduate Research Students (ReMentURS) workshop series is to design a remotely available professional development training that will provide rigorous research concept and skills introduction to incoming undergraduate research students. This pilot run eight-week remote learning workshop series includes digital presentations, informational videos, virtual demonstrations, and aligned comprehension checks to foster student mindsets towards becoming independent research scientists. Preliminary assessment of the of ReMentURS program reveals that participants self-report gaining a variety of skills through the series and are likely to use the content in their future course and research laboratories. ReMentURS material can be shared with any undergraduate student who is interested in joining a research group to familiarize them with basic research techniques. Student learning gains will continue to be evaluated throughout the series and this initial assessment will be used towards the betterment of the future workshops.
\end{abstract}

\section{Keywords}

Remote Mentoring, Undergraduate Research Student, Virtual, Professional Development, ReMentURS

\section{Creative Commons License}

\section{(c) (i) $\ominus$}

This work is licensed under a Creative Commons Attribution-Noncommercial-No Derivative Works 4.0 License.

\section{Cover Page Footnote}

The ReMentURS team acknowledges and is grateful for the funding provided by Affordable Learning Georgia - Continuous Improvement Grant - Proposal M141. Our team is highly appreciative of the expertise and contributions provided by Dr. Debanjana Ghosh, Dr. Beulah Narendrapurapu, Dr. Kania Greer, Dr. Eric Johnson, Dr. Gwendolyn Caroll, Dr. Stephen Carden, Mrs. Amanda Klingel, and Mrs. Malorie Rivera in development and review of module content. We are thankful to Prof. Jessica Orvis, Dr. Diana Botnaru, and Dr. Karelle Aiken for providing edits. The support provided by Dean Delana Gajdosik-Nivens, Dr. Will Lynch, Dr. Amanda White (SAACS), Mr. Jeffrey Mortimore (Institution 1 Library), Mr. Daniel Rivera (Instructional Support and Resources Center; Director for First District RESA), Ms. Deborah Walker (The Faculty Center) and our Institution 1 Student Affiliates of the American Chemical Society (SAACS) team members; Department of Chemistry and BioChemistry, Department of Biology, McNair Program are highly appreciated. The authors also greatly acknowledge the funding provided to the research students participating in this project - i) University System of Georgia STEM Education Improvement Grant, Phase IV; ii) NIH-NIBIB-ESTEEMED (5R25EB025768-02); iii) NSF-iAPPLY (2011969).

Authors

Elizabeth Sargent, Abid Shaikh, Karla Sue Marriott, Taysia Porter, Dawn N. Cannon-Rech, and Shainaz M. Landge 


\title{
Introducing the Remote Mentoring of Undergraduate Research Students (ReMentURS) Workshop Series: Initial Evaluation and Plans for Wider Implementation
}

\author{
Elizabeth Sargent', Abid Shaikh', Karla Sue Marriott², Taysia Porter', Dawn N. Cannon-Rech', and Shainaz M. Landge' \\ I. Georgia Southern University \\ 2. Savannah State University; Roger Williams University
}

Received: 7 September 2021; Accepted: 23 November 2021

\begin{abstract}
The primary objective of the Remote Mentoring of Undergraduate Research Students (ReMentURS) workshop series is to design a remotely available professional development training that will provide rigorous research concept and skills introduction to incoming undergraduate research students. This pilot run eight-week remote learning workshop series includes digital presentations, informational videos, virtual demonstrations, and aligned comprehension checks to foster student mindsets towards becoming independent research scientists. Preliminary assessment of the of ReMentURS program reveals that participants self-report gaining a variety of skills through the series and are likely to use the content in their future course and research laboratories. ReMentURS material can be shared with any undergraduate student who is interested in joining a research group to familiarize them with basic research techniques. Student learning gains will continue to be evaluated throughout the series and this initial assessment will be used towards the betterment of the future workshops.
\end{abstract}

\section{INTRODUCTION}

For sciences, research is generally conducted with hands-on activities and in-person laboratory training. (Unal et al., 2008; Hensiek et al., 2016; Serafin et al., 2020) In emergency and unprecedented situations that prevent students from accessing laboratories and research groups, such as COVID-19 and natural disasters, students lose valuable face-to-face training opportunities. (Donnelly et al., 2013; Dalgarno et al., 2009) Undergraduate research (UR) has shown to increase student motivation and self-efficacy leading to persistence in STEM fields. (Eagan et al,, 20I3; Kerr et al., 2020; Kinkel \& Henke, 2006; Lopatto, 2007) Student engagement in UR has numerous benefits. It helps students to develop soft skills, basic research methods, lab preparation techniques, instrumentation training, professional etiquette, and scientific literacy (writing and presenting).(Rodenbusch et al., 20I6; Beckham et al., 20I5) UR also helps students to think and become more like a scientist, and guides them towards applying to graduate schools and pursuing various internships and awards.(Schneider et al., 202I) It aids students in their professional branding as a member of the scientific community and makes them more STEM ready! (Stanford et al., 2017; Wladis et al., 2015)

To enhance the Undergraduate Research Experience (URE) various notable initiatives have been nationally implemented such as Freshman Research Initiative (FRI), (Beckham et al., 20I5; University of Texas at Austin Texas, 2019) Course Based Undergraduate Research Experiences (CUREs) (Bangera \& Brownell, 20I4; Corwin et al., 20I5) mini-CUREs (Bell et al., 20I9; Tootle et al., 2019), the McNair-TRIO program, and many others. To increase student participation and retention in UR it is imperative to consistently provide them with professional development (PD) skills through multiple pathways so that learning can continue uninterrupted. (Eagan et al., 20I3) The COVID-I 9 pandemic has hampered the consistent delivery of UR opportunities and has challenged the continuity of mentorship more difficult.

\section{DEVELOPMENT OF REMOTE MENTORING PROGRAM}

Desperate situations call for creative solutions and hence the idea for Remote Mentoring of Undergraduate Research Students (ReMentURS) took shape in the summer of 2020.This workshop series was developed in direct response to physical distancing and remote course offerings due to the COVID-19 pandemic. Despite its beginnings, the benefits of this workshop series may extend beyond the immediate pandemic-related need for emergency remote mentorship. ReMentURS has been designed to continue to support research students with high quality remote mentorship and training to better prepare and support them ahead of or at the onset of joining a research lab with an individual mentor. Additionally, it will be beneficial for even non-STEM students, such as those needing support during completion of the CORE science required course.

At primarily undergraduate institutions (PUls), undergraduate (UG) students are the major workforce that carries out campus research. (Dahlberg et al., 202I; Sens et al., 2017) Providing formal training through the ReMentURS virtual platform is a creative method to help ensure undergraduates are prepared for research experiences regardless of whether in person access to laboratories is available. Through ReMentURS series, we plan to develop human capital for the greater scientific community and promote continuing STEM education even in virtual conditions. The idea is to provide students with focused, planned PD activities through eight weeks of comprehensive training to nurture undergraduate scholars' exploratory minds. An intense and diverse high-quality research experience, along with the supportive growth mindset environment will enhance students' learning processes. ReMentURS modules will be made publicly available to increase access and training opportunities for all UR scholars. These materials will also be a valuable resource (repository) for any institution that for any reason (natural disaster or public health related) faces research training closures. 


\section{Development of the modules - Virtual plan}

The full ReMentURS series covers many aspects necessary to develop undergraduates into effective researchers including - professional etiquette training, an introduction to laboratory safety and scientific ethics, basic lab skills and instrument training sessions, practice reading and writing scientific literature, and information literacy. Information literacy plays an important role in scientific literacy, and it's not always an area emphasized when mentoring students in scientific research. Scientific Information Literacy includes, but is not limited to, synthesizing ideas gathered from multiple sources, identifying gaps in knowledge within their discipline, matching information needs and search strategies to appropriate search tools, designing and refining needs and search strategies as necessary, and correctly citing others work and providing appropriate credit for the original ideas of others. (Kerr et al., 2020; Kinkle \& Henke, 2006; Mabrouk \& Peters, 2000; Hunter et al., 2007)

Focusing more on the remote mentoring of research scholars aspects, special attention was given to the basic lab skills, instrument training, information and scientific literacy mastery in mind, an eight-week workshop series was created and a pilot study was launched for initial assessment of participants. Professional etiquettes, safety, ethics, scientific and information literacy was targeted step by step. Each of the eight modules were developed to target skills within specific aspects beneficial to new student researchers and are detailed in Table I. These modules include training videos and/or activities as well as templates, worksheets, and surveys for comprehension checks and assessment purposes. Each module is designed so that students are expected to commit I to 2 hours per week to engage and complete the activities. The consistent design of and repetition of expectations and assess- ments within each module sets the tone for remote workshop behavior and serves as an additional benefit in preparing students to succeed in other online courses or remote work environments.

For various module topics, experienced faculty and administrators with corresponding expertise were called upon to collaborate on creation and review of module content. For example, information literacy training was developed by a library liaison, time management training was lead by an academic advisor, the data and statistics module was built by math faculty, and scientific figure creation training was demonstrated by researchers using this software in their own laboratories. All module contributors are acknowledged at this end of this manuscript. In this regard, ReMentURS series exposes UR scholars to a broader suite of research methods and skills than they might otherwise be exposed to in a single mentor's laboratory. Conversely, the addition of all the targeted and selected skills covered in this series provides an opportunity for faculty research mentors to devote more of their time to supporting students in aspects of a specific research project rather than trying to additionally balance that mentorship with broader training.

\section{MODULE DETAILS}

\section{Module 1}

Professional Etiquettes and Time Management introduces participants to soft skills through a virtual introduction with ReMentURS leaders and research mentors followed by structured learning about etiquettes, such as "how to write an email" (professional etiquettes) and "how to present themselves" in a virtual setting (Netiquettes). Module I also addresses time management very early on through a "how to manage the time" video. Students self-assess their etiquette and time management skills through

\begin{tabular}{|c|c|c|c|}
\hline \multirow{2}{*}{ Module } & \multicolumn{2}{|c|}{ Participant Engaged Materials } & \multirow{2}{*}{$\begin{array}{l}\text { Participant Work } \\
\text { Completed }\end{array}$} \\
\hline & Videos & Readings & \\
\hline $\begin{array}{l}\text { Introduction } \\
\text { ReMentURS Team and information }\end{array}$ & & Main page & \begin{tabular}{|l|} 
Informed Consent \\
Pre survey
\end{tabular} \\
\hline \multirow[t]{2}{*}{$\begin{array}{l}\text { I - Professional Etiquette and Time } \\
\text { Management }\end{array}$} & $\begin{array}{l}\text { - How to Write an Email } \\
\text { - Netiquette } \\
\text { - Time Management }\end{array}$ & & Worksheets and Template \\
\hline & & & Workshop Survey \\
\hline \multirow[t]{2}{*}{2 - Safety and Ethics } & \begin{tabular}{|l} 
Lab Safety \\
- Science Ethics
\end{tabular} & & $\begin{array}{l}\text { Worksheet and } \\
\text { Case Studies }\end{array}$ \\
\hline & & & Workshop Survey \\
\hline \multirow[t]{2}{*}{$\begin{array}{l}\text { - Literature Search and Reading } \\
\text { Scientific Literature (Sci. Lit.) }\end{array}$} & $\begin{array}{l}\text { What is Sci. Lit.? } \\
\text { - How to find Sci. Lit. }\end{array}$ & Where to find Sci. Lit. & Worksheets \\
\hline & & & Workshop Survey \\
\hline \multirow[t]{2}{*}{4 - Citing References } & $\begin{array}{l}\text { Endnote } \\
\text { Google Citation }\end{array}$ & & Worksheets \\
\hline & & & Workshop Survey \\
\hline \multirow[t]{2}{*}{5 - Data Management } & $\begin{array}{l}\text { Excelling in Excel } \\
\text { - Choosing a Graph }\end{array}$ & & Worksheets and Template \\
\hline & & & Workshop Survey \\
\hline \multirow[t]{2}{*}{6 -Data Analysis and Statistics } & $\begin{array}{l}\text { Scientific Calculators } \\
\text { - Statistical Analysis } \\
\end{array}$ & & Worksheets \\
\hline & & & Workshop Survey \\
\hline \multirow[t]{2}{*}{7 - Making Figures and Schemes } & $\begin{array}{l}\text { ChemDraw - Schemes } \\
\text { Figures in Powerpoint }\end{array}$ & & Worksheets \\
\hline & & & Workshop Survey \\
\hline \multirow[t]{2}{*}{8 - Scientific Writing and Reading } & - How to read Sci. Paper & THE ACRES & Worksheets \\
\hline & & & $\begin{array}{l}\text { Workshop Survey } \\
\text { Post survey }\end{array}$ \\
\hline
\end{tabular}


digital worksheets and a template provided for participants to track and manage their academic progress and research commitments.

\section{Module 2}

Safety and Ethics in Research begins with a video presentation on safe laboratory practices and showcases "the do's and don'ts in the lab settings." Participants also engage with content related to scientific ethics in this module and complete corresponding worksheets for self-assessment. Scientific ethics is addressed early in the ReMentURS series to stress the importance of ethics in the scientific community and in global society

\section{Module 3}

Scientific Literature and Literature Search provides participants with information on effective use of campus library resources and on-line databases (e.g. SciFinder and Web of Science). This module focuses on "where and how to find the scientific literature". Consistent with modules I and 2, this module is presented via video introductions, supplemented with readings and self-assessment worksheets, which are provided for guided literature searching and creating an effective search strategy.

\section{Module 4}

Citing Resources and Writing References provides information on "how and why to create a bibliography" when composing scientific writing. The two main citation products discussed in this module are Endnote and Google Citation. As with prior modules, participants self-assess with citation management worksheets.

\section{Module 5}

Data Management introduces participants to the "basics of Microsoft Excel" for data sorting and graphing purposes. Participants are provided with an Excel template to follow along and create figures. This module also includes a video on which graph type to choose based on your research question and dataset.

\section{Module 6}

Calculator and Statistics includes videos on "how to effectively use a scientific calculator" (basic techniques) and "how to do the basic statistical analysis" for data processing. Worksheets are provided for self-assessment and practice with these concepts.

\section{Module 7}

Creating Figures and Schemes introduces scientific figure generation, which is a vital skill for any participant planning to present or publish their research. This module specifically demonstrates the creation of chemistry schemes in ChemDraw and the creation of more generic schemes in Microsoft PowerPoint. Worksheets are provided for self-assessment.

\section{Module 8}

Knowing and Reading a Scientific Paper covers the plot of scientific literature and "how to read as well as compose a scientific paper". As with previous modules, participants can self-assess their mastery of these concepts through the digital "THE ACRES" template worksheets.

\section{TARGETED POPULATION FOR THE ReMEntURS WORKSHOP SERIES}

The most affected student population for this study are the scholars who for any reason (natural calamity or personal) were unable to conduct research in a "face-to-face" setting or who required training at the start of or before beginning research in a laboratory. So, students in any research program/setting could be appropriate candidates for the ReMentURS workshop series. This multi-institutional collaborative pilot study of the ReMentURS series was conducted at two universities (Georgia Southern University and Savannah State University). Georgia Southern and Savannah State were already involved in an intercampus remote mentorship collaboration and served as a perfect fit for the ReMentURS series pilot study; which was conducted during summer term.

At Georgia Southern, URs working during summer term in research labs are typically participating in the following programs and in current study:

I. Summer Undergraduate Research Experience (SURE) program - This program is sponsored by the Department of Chemistry and Biochemistry and is aimed at providing research experience to UR's for the summer term at Georgia Southern.

2. Incorporation of Freshmen in Research for Early Experience (iFREE) - a program initiated at Georgia Southern where students are exposed to research in their Freshman year. Two of the developing team members of the ReMentURS workshop series are also iFREE leaders at two different campuses.

3. McNair Program - open for any first-generation, underrepresented minority, financially disadvantaged student or underserved population who are interested in conducting research. It targets rising juniors and seniors.

At Savannah State, URs present during the summer 202I term were participating in team-based research projects through the following programs and in current study:

I. Achieving Diversity through Integrative Scientific Research Experience (ADISRE) - This is a five year (20182023) National Institutes of Health NIBIB-ESTEEMED student-centered research education program that aims at "Creating A Desire" for learning and the ethical application of useful scientific information.

2. iApply: the "Early Interdisciplinary Applied Strategies to Strengthen STEM Education and Research" program at Savannah State is about early engagement of STEM students with immersive, interactive and relevant interdisciplinary applications of science. This grant funded through the NSF aims to strengthen Savannah State's traditional undergraduate research training model through a team-based applied/interdisciplinary training approach.

These are only a select few of the research programs running during summer term at Georgia Southern and Savannah State, and are similar to programs running at other PUls.

\section{MODULE HOSTING AND DISSEMINATION OF THE PRODUCT}

The generated product is hosted as an Open Educational Resource (OER) on the Library Guides (LibGuides) platform of the Georgia Southern library website and is available for access to the wider scientific community beyond Georgia Southern and Savannah State. (supporting information) The ReMentURS workshop series links will also be shared with the State University System host website. All the materials follow the open licensing protocol and are shared with a creative common's attribution (CC-BY). LibGuides is a well-suited platform for this project. The 
LibGuides platform offers the creators the ability to provide a unique look and feel for each guide. Additionally, since access and permission controls are applied at the guide administrator level, library administrators are able to cordon off guides from each other and from platform-level configurations. (Rech \& Mortimore, 2020) In this way, administrators can open up highly customized guides to faculty editors while protecting library-created content. It offers hosting and access that is extremely flexible in terms of content, display, and accessibility controls to meet the needs of other institution or student needs beyond Georgia Southern and Savannah State.

Each week of the summer pilot study, individual LibGuide modules were opened to the Georgia Southern and Savannah State students and a reminder email was sent to encourage participation. Periodic feedback was collected from students on each module and from research mentors. Modules were amended and adjusted accordingly to prepare for releasing the ReMentURS workshop series to the wider public in the upcoming semesters.

\section{RECRUITMENT}

Students in a variety of STEM disciplines at Georgia Southern and Savannah State in the southeastern United States were recruited during the spring and summer of 2021 at the onset of their research experience with individual mentors or summer research programs. The ReMentURS workshop series was offered to these students in addition to the specific training and support they were receiving individually from those mentors/programs. Students under the age of 18 were not included in this study. Prior to completing any ReMentURS workshop content, participants were asked to complete informed consent, which was provided digitally through the LibGuides platform. A total of thirteen students chose to begin the ReMentURS workshop series and consented to participate in this preliminary study (IRB\#H2 I426). Participants were subsequently grouped by level and focus area as indicated on the pre survey for further analysis (see Table 2).

\begin{tabular}{|c|c|c|c|}
\hline $\begin{array}{l}\text { Level and } \\
\text { Focus Area }\end{array}$ & $\begin{array}{c}\text { Pre survey } \\
(n=12)\end{array}$ & $\begin{array}{l}\text { Post survey } \\
(n=8)\end{array}$ & $\begin{array}{l}\text { Completed work- } \\
\text { shop series }(n=7)\end{array}$ \\
\hline $\begin{array}{l}\text { Undergraduate } \\
\text { biology }\end{array}$ & $16.7 \%$ & $12.5 \%$ & $14.3 \%$ \\
\hline $\begin{array}{l}\text { Undergraduate } \\
\text { chemistry }\end{array}$ & $33.3 \%$ & $37.5 \%$ & $28.6 \%$ \\
\hline $\begin{array}{l}\text { Undergraduate } \\
\text { other* }\end{array}$ & $33.3 \%$ & $37.5 \%$ & $42.8 \%$ \\
\hline $\begin{array}{l}\text { Graduate } \\
\text { chemistry }\end{array}$ & $16.7 \%$ & $12.5 \%$ & $14.3 \%$ \\
\hline
\end{tabular}

\section{INSTRUMENTS AND DATA COLLECTION}

A mixed method, but primarily qualitative approach was used to assess a combination of student performance and perception data related to scientific research. A pre and post survey was delivered at the beginning and end of the workshop series to assess student motivations for participating in the workshop, expectations for and likelihood of future use of workshop module content, and perspectives on learning and skill gains over the course of the workshop series. Pre and post survey questions are included here:

Pre survey open response questions:

- What is your main reason for participating in the Re- mote Mentoring of Undergraduate Research Students (ReMentURS) workshop series?

- Which workshop are you most looking forward to during your participation in ReMentURS?

- Briefly describe what you expect to learn and what skills you expect to develop from this workshop series.

Post survey open response questions:

- What was your main reason for participating in the Remote Mentoring of Undergraduate Research Students (ReMentURS) workshop series?

- Which workshop did you most enjoy during your participation in ReMentURS?

- Briefly describe what you learned and what skills you developed from this workshop series.

Pre and post survey Likert Scale questions:

- How likely do you think it is that you will use what you learn in this workshop series in your future undergraduate courses?

- How likely do you think it is that you will use what you learn in this workshop series in your future research project?

Individual module surveys were also delivered each week to assess participant-specific learning gains. Intra-module comprehension checks were administered as digital worksheets related to delivered content to assess content and skill mastery. These varied by exercise and provided an opportunity for participant self-assessment during each module. Due to the preliminary nature and sample size of this pilot study, only the pre and post survey data is discussed herein.

All surveys and worksheets were delivered remotely through Google Forms linked on the LibGuide platform. No identifiable data was collected or stored. Participants were instead asked to create and use an anonymous identifier in each survey, which allowed for data pairing. No incentives were provided to participate in or complete the ReMentURS modules. Additionally, no penalty to students results from participation in this series as all have access to the same PD activities and participation is voluntary. Classroom and lab instruction time is not required to participate. All participants retain asynchronous access to the ReMentURS LibGuides platform in perpetuity.

\section{ANALYSIS}

Pre and post survey summary data were used to determine participant level and focus area. Text analysis of pre and post survey responses, including word frequency, collocation, and concordance, was performed to assess participant motivations, expectations, and research knowledge and skill gains via self-assessments. Mean procedures for a five-point Likert scale analysis were performed to determine the likelihood that participants will use ReMentURS content in their future courses and/or research. Pre and post survey data were compared using two tailed, paired t-test to assess statistical significance of perceived changes over the course of the workshop series.

\section{RESULTS \\ Participant characteristics}

Thirteen summer research students were recruited to participate in the ReMentURS program from two institutions in the southern United States. Of those, 12 completed the pre survey, eight completed the post survey, and seven (53.8\%) completed 
the entire workshop series including pre and post surveys within the assessment period. Participants varied in their academic level and focus area with the majority of participants being undergraduates with an interest in chemistry and non-biological STEM fields (Table 2).

\section{Motivation for participating in the workshop series}

Of the 12 students that began the ReMentURS workshop series and completed the pre survey, $42 \%$ mentioned a desire to learn or develop research skills during their participation in the workshop series, while $33 \%$ cited a direct request by a mentor or professor to participate. The remaining participants stated a desire to give and receive feedback and/or recognized a future benefit to completing the workshop series, such as looking back on the modules for future reference and contributing to mentorship of future research students. All students who were directly requested to participate or who desired feedback completed the entire workshop series (Figure I).

\section{Individual module enjoyment}

Of the seven participants who completed the entire ReMentURS workshop series, only one predicted their true module of highest enjoyment at the outset of the workshop. All others differed in their indicated modules of predicted highest enjoyment (pre survey) and modules of experienced highest enjoyment (post survey) (Figure 2). Module five: data analysis - making data bearable was most indicated as the module of predicted highest enjoyment ( $41.7 \%$ of pre survey respondents), while the modules of experienced highest enjoyment were jointly module two: safety and ethics ( $25 \%$ of post survey respondents), module five: data analysis - making data bearable ( $25 \%$ of post survey respondents), and module eight: scientific writing and reading ( $25 \%$ of post survey respondents).

\section{Likelihood of future use}

Pre and post survey participant-indicated likelihood of use of workshop content in future courses and research was rated highly

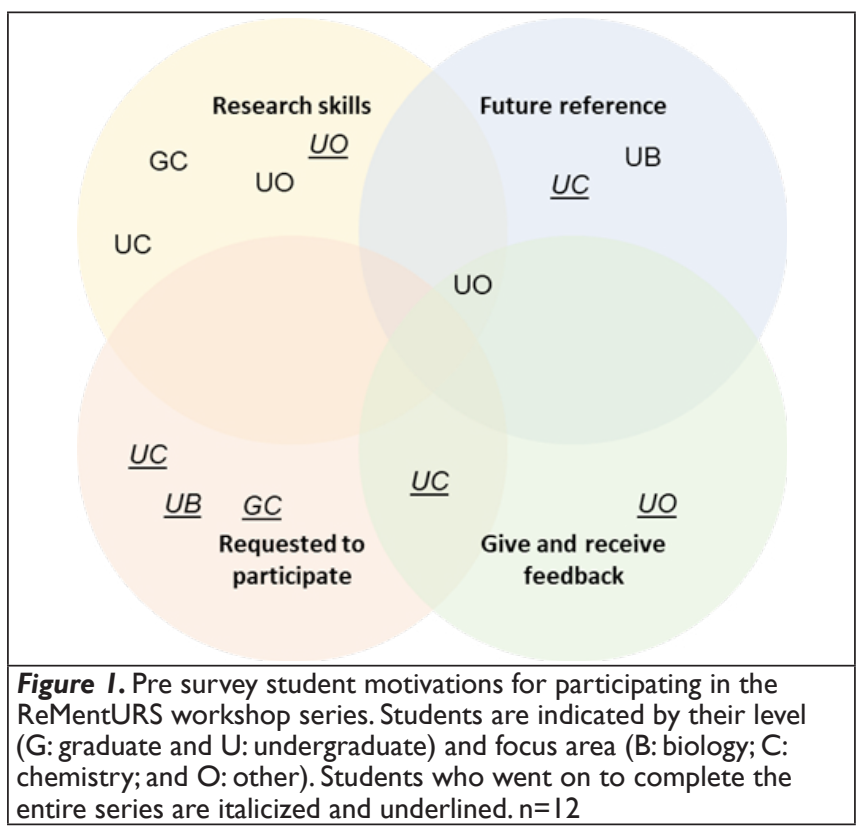

among the seven students who completed the entire workshop series, including pre and post surveys $(n=7)$. A two tailed, paired t-test revealed mean student perception of the value of workshop content in their future courses significantly increased between the pre and post surveys $(3.7 \pm 1.4$ pre and $4.4 \pm 0.8$ post; $p<0.05)$. Though not statistically significant, mean student perception of the value of workshop content in their future research also increased between the pre and post survey $(4.3 \pm 0.8$ pre and $4.7 \pm 0.5$ post; $p>0.05$ ) (Figure 3).

\section{MAJOR FINDINGS}

Text analysis of the 335 words composed by the eight participants who completed the post survey in response to the question "briefly describe what you learned and what skills you developed from this workshop series" revealed few common themes. Instead, each participant specifically detailed different aspects of the workshop series that benefitted them personally. No two

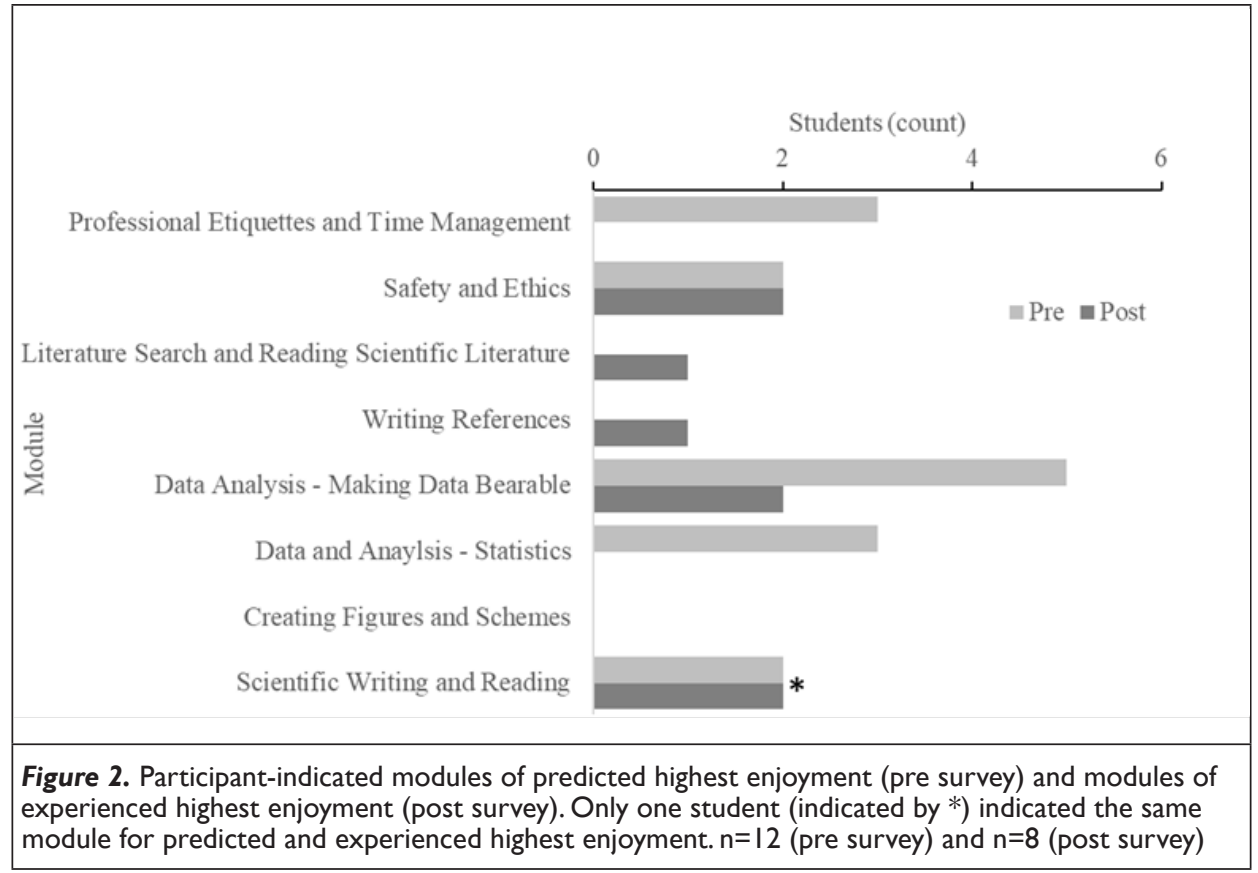




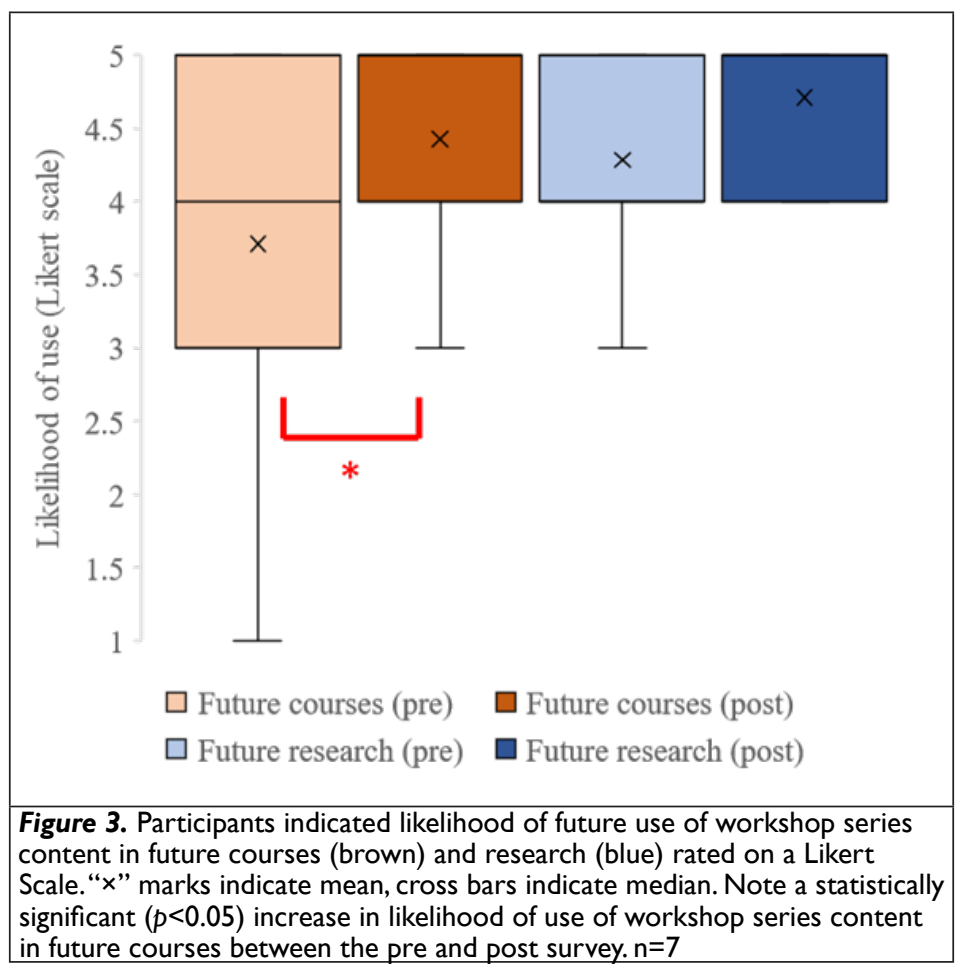

participant responses mentioned the same learning or skill gain metrics, though some did mention metrics covered under the same modules. For example, one student detailed learning citation hacks (shortcuts in Google Docs) while another mentioned learning how to write a citation; both of these are covered under Module Four: Citing References but are distinctly different skills. Participants also individually mentioned skill gains relating to specific software (ChemDraw, Microsoft Office Suite, and Google Workspace); a greater appreciation for lab safety and scientific ethics; increased confidence in reading and searching scientific literature; or becoming more proficient at developing research questions, analyzing scientific data, and creating figures. These metrics fell under each of the eight modules in the ReMentURS workshop series (see Table 3).

Each individual module also included content-based assessment. During the scientific writing and reading module 8 , students were asked to list the components of a research paper in order

\begin{tabular}{|l|c|c|}
\hline $\begin{array}{l}\text { Table 3. Post survey participant-indicated metrics of learning and } \\
\text { skill development over the course of the workshop series. n = 8 }\end{array}$ \\
\hline & $\begin{array}{r}\text { \# of participants } \\
\text { indicating metric }\end{array}$ \\
\hline Module Covering Metric Mentioned & Learned & $\begin{array}{c}\text { Skills } \\
\text { Developed }\end{array}$ \\
\hline Professional Etiquettes and Time Management & I & I \\
\hline Safety and Ethics & 2 & I \\
\hline Literature Search \& Reading Scientific Literature & I & 2 \\
\hline Writing References & I & I \\
\hline Data Analysis - Making Data Bearable & I & I \\
\hline Data and Analysis - Statistics & I & I \\
\hline Creating Figures and Schemes & I & 2 \\
\hline Scientific Writing and Reading & & \\
\hline Note: some participants listed more than one metric for both learning and \\
\hline
\end{tabular}

before and after completing the module. None of the seven participants who completed this module were able to list the components in order at the beginning, while three were $100 \%$ accurate at the end of the module, with the other four only making minor errors, such as swapping the order of authors and author affiliations or swapping results and discussion with conclusions sections.

\section{DISCUSSION \\ Study Limitations}

As the sample size of this pilot study is small, and thus the statistical power of our assessment is limited, these results should be considered conservative and preliminary. Data analysis will continue as the ReMentURS program expands to a wider audience. The use of self-reported data in participant assessment of learning gains should be noted.The use of self-reported learning gains as valid measures of learning is debated in the literature. While there is some evidence that STEM students can self-identify broad gains within their discipline (Pace et al.; 1985) and more specifically in skill and concepts related to research (Weston \& Laursen et al.; 2015), there is also evidence that college students are unable to accurately self-report specific learning gains (Porter et al.; 20I3). Objective measures of learning gains using a pre/post content assessment survey are planned for future iterations of the ReMentURS workshop series to substantiate the preliminary findings discussed here.

It should also be noted that our assessment of participant-reported enjoyment of ReMentURS modules as well as the skills and learning outcomes reported by student were facilitated by open-ended responses to pre and post survey questions. While we feel the themes and subthemes, we identified are valid, they are inherently limited by our study design. While we did not explicitly ask why participants answered the way that they did, many responders volunteered this information in their written responses. We have adjusted future iterations of this assessment 
to explicitly as why so that we can build off of this analysis during wider program rollout.

\section{Recruitment and motivation}

Even though recruitment of participants in this pilot study was limited to only two institutions, this population of students spanned multiple summer research initiatives and included multiple student levels and focus areas (Table 2). With such a diverse group it is perhaps unsurprising that motivations for participating in the ReMentURS series were variable. Predominantly, participants classified a desire to learn or develop research skills as the reason for being interested in completing the ReMentURS series. A slightly lower proportion of participants instead cited a direct request by a professor to participate and others were split on a desire to give and receive feedback and/or recognizing a future benefit to completing research training through ReMentURS (Figure I). Attrition over the course of the workshop series was seen in the groups who expressed motivations strictly aligned with learning or developing research skills. Conversely, every participant who was directly requested to participate or who desired feedback through ReMentURS went on to complete the entire series.

An analysis by Lopatto (2003) revealed undergraduate research students often cited developing a continuing relationship with a faculty member as one of the most important benefits they would derive from a research experience, perhaps indicating that ReMentURS is most effective when coupled with encouragement from primary mentors. Participants whose motivations were related to direct requests and feedback desires were also the most diverse in terms of level and focus area. This indicates that even though this initial evaluation of the ReMentURS series results from recruitment at only two institutions and limited summer programs, a wider implementation to other URs when coupled with support from primary mentors would be beneficial to students and mentors alike considering the broad soft and professional skills provided by this workshop series. Even non-STEM students, such as those completing science courses to fulfill a core science degree requirement, can participate in and benefit from ReMentURS as early UR experiences have been shown to result in similar learning gains for STEM and non-STEM UGs.(Stanford et al., 2017)

Undergraduate research has been documented as an important component improving underrepresented racial group persistence in STEM (Chang et al., 2014) and remote learning provides non-traditional students with opportunities they might otherwise not have access to.(Wladis et al., 20I5) As a remote, undergraduate research support series, ReMentURS is a perfect blend of research training, offering the flexibility of asynchronous remote instruction and providing opportunities to a diverse group of students. Previous studies have demonstrated no significant differences in student performance when comparing remote learning and face-to-face instructional modes in some STEM courses (Paul \& Jeffeerson, 2019) so ReMentURS may also offer similar student outcomes when compared to more traditional in person research training.

\section{Self-reported learning gains and preliminary learning gains}

In addition to variation in motivations for participating in the ReMentURS series, there was also variation in the specific modules each participant looked forward to at the beginning of the workshop and enjoyed the most at the end of the workshop. Only one participant predicted their true module of highest enjoyment at the outset of the workshop and five of the eight modules were indicated by participants at the end of the series (Figure 2). Additionally, there was no consistency in the skills gained and concepts learned cited by participants at the end of the series. Metrics of learning and skill development indicated by individual participants spanned all eight of the ReMentURS modules (Table 3). Taken together, it appears ReMentURS may be able to function like a Just in Time Teaching (JiTT) tool. Unlike traditional JiTT where instructors adapt content delivery in response to student performance on formative assessments and through active learning (Novak et al., 1999) ReMentURS is adaptive and active learning by default. By providing such a broad range of professional development topics, skills, and activities, it is essentially meeting students where they are and filling in the gaps in learning and skills specific to each individual.This targeted bridging of gaps may allow each participant to gain confidence in their research knowledge and become more capable of applying a variety of research skills in their projects with their individual mentors following their participation in the ReMentURS workshop series.

It appears that learning is also happening outside of solely what students report as their gains. Only one student self-reported learning a new concept and no students self-reported learning any skills in the final scientific writing and reading module, but all students who completed that module improved on their ability to identify and organizes components of a research paper following their interaction with module content. A broader objective analysis of learning gains for each module is in development for further iterations of the ReMentURS program.

In addition to their self-assessment of learning and skill gains, participants were asked to rate the likelihood of future use of ReMentURS content in their future courses and research. Participants were equally likely to rate the likelihood of use of ReMentURS content in research at the beginning and end of the series, whereas the mean student perception of the value of workshop content in their future courses significantly increased over the course of the series (Figure 3). Not only does participation in research training, such as ReMentURS coupled with individual research projects, lead to increased retention of undergraduate students, (Stanford et al., 2017) but it may also serve to better prepare participants for their future courses. Other research support and training programs have been shown to increase participant GPAs, graduation rates, graduation speed, and success in obtaining jobs in STEM. (Kinkle \& Henke, 2006) Thus, not only does the ReMentURS workshop series help students to generate a good scientific understanding and appreciation of research, but it may also help them in the pursuit of their degree and beyond.

\section{FUTURE IMPLICATIONS AND CONSIDERATIONS}

The authors are currently building two additional modules focused on scientific writing and presentation of scientific results, which will make the ReMentURS program a I0-week workshop series. These two final scientific literacy modules will include "how to write specific sections of scientific peer-reviewed publications" and "how to make and present a scientific poster" and will be supplemented by templates and self-assessment worksheets. 
Instrumentation as a part of modern technology requires scientists to be well-trained in synthesis and characterization of materials. The goal was to introduce UR student to laboratory settings and offer resources that are available under extenuating circumstances. In addition, most of the material taught in science classes is ultimately based on theories that were developed from experimental results. It is therefore important to introduce students to the concept of scientific research. (Lopatto, 2007) Not only can such an experience stimulate their interest in science in general, and chemistry in particular, it will also help them to decide whether science is the right choice for them. In addition to the currently provided module content, the authors will have an optional instrument training module for equipment commonly used in science laboratories, such as pipetting, gas chromatography, infrared spectroscopy, chemistry and biology lab techniques. Not all research students will utilize all the instruments present in the modules during their research. Hence a mix of chemistry and biology instrument training videos will be included, demonstrating basic laboratory techniques used in research to provide a general introduction to the types of techniques and analysis involved in STEM research. The ReMentURS team has already completed short video demonstrations and operation instructions for thin layer chromatography, column chromatography, distillation, infrared spectroscopy, and gas chromatography that can be shared with students that are interested in working in any research lab. The material can be disseminated to undergraduate, graduate and summer research students as needed.We anticipate these newly developed resources will build scientific confidence and competence among students as previous research in STEM education has documented that directed, self-guided exposure to methods and techniques builds confidence and competence in subsequent workplace experiences. (Kerr et al., 2020)

Future changes are also being considered in the scientific information literacy modules. These include adding an opportunity to perform searches for known and unknown information, and a demonstration using open-access software. Georgia Southern library is also in the process of adding case studies to the Data Management modules as well as in the Scientific Ethics modules. These developments will enhance the experience of students and strengthen their exposure to each of these topics.

Each of these modifications will make the ReMentURS program a one-stop workshop for undergraduate research scholars to virtually visit and get training before and during their research experiences. Students can also re-visit the modules when they want to learn or remember the information (instrument, safety, ethics, writing) at any time. Our final goal is to expand access to and assess student success of ReMentURS in CORE research courses with a wider rollout, where URs are trained to think and act like scientists regardless of their major.

\section{SUPPORTING INFORMATION}

\section{ReMentURS LibGuides Webpage}

\section{ACKNOWLEDGEMENTS}

The ReMentURS team acknowledges and is grateful for the funding provided by Affordable Learning Georgia - Continuous Improvement Grant - Proposal MI4I. Our team is highly appreciative of the expertise and contributions provided by Dr. Debanjana Ghosh, Dr. Beulah Narendrapurapu, Dr. Kania Greer, Dr. Eric Johnson, Dr. Gwendolyn Caroll, Dr. Stephen Carden, Mrs. Amanda
Klingel, and Mrs. Malorie Rivera in development and review of module content. We are thankful to Prof. Jessica Orvis, Dr. Diana Botnaru, and Dr. Karelle Aiken for providing edits. The support provided by Dean Dr. Delana Gajdosik-Nivens, Dr. Will Lynch, Dr. Amanda White (SAACS), Mr. Jeffrey Mortimore (Georgia Southern Library), Mr. Daniel Rivera (Instructional Support and Resources Center; Director for First District RESA), Ms. Deborah Walker (The Faculty Center) and our Georgia Southern Student Affiliates of the American Chemical Society (SAACS) team members; Department of Chemistry and BioChemistry, Department of Biology, McNair Program are highly appreciated. The authors also greatly acknowledge the funding provided to the research students participating in this project - i) University System of Georgia STEM Education Improvement Grant, Phase IV; ii) NIH-NIBIB-ESTEEMED (5R25EB025768-02); iii) NSF-iAPPLY (2011969).

\section{REFERENCES:}

Bangera, G., \& Brownell, S. E. (20|4). Course-based undergraduate research experiences can make scientific research more inclusive. CBE-Life Sciences Education, I3(4), 602-606.

Beckham, J.T., Simmons, S., Stovall, G. M.; Farre, J. (20।5). The freshman research initiative as a model for addressing shortages and disparities in STEM engagement. Directions for Mathematics Research Experience for Undergraduates, WORLD SCIENTIFIC, I8I-2I 2 .

Bell, J., Provost, J., Bell, E. (2019, September). A Community based CURE project to explore structure-function relationships in Malate Dehydrogenase. In Protein Society Annual Symposium.

Chang, M. J., Sharkness, J., Hurtado, S., Newman, C. B. (20I4). What matters in college for retaining aspiring scientists and engineers from underrepresented racial groups. Journal of Research in Science Teaching, 5 I (5), 555-580.

Corwin, L. A., Graham, M. J., Dolan, E. L. (20I5). Modeling course-based undergraduate research experiences:An agenda for future research and evaluation. CBE-Life Sciences Education, I 4(I), es I.

Dahlberg, C. L. L., King-Smith, C., Riggs, B. (202I). Building a laboratory at a Primarily Undergraduate Institution. BMC proceedings. I5(2), I-7. BioMed Central. Springer

Dalgarno, B., Bishop, A. G., Adlong,W., Bedgood Jr, D. R. (2009). Effectiveness of a virtual laboratory as a preparatory resource for distance education chemistry students. Computers \& Education, 53(3), 853-865.

Donnelly, D., O’Reilly, J., McGarr, O. (20I3). Enhancing the student experiment experience:Visible scientific inquiry through a virtual chemistry laboratory. Research in science education, 43(4), I57I-I 592.

Eagan Jr, M. K., Hurtado, S., Chang, M.J., Garcia, G. A., Herrera, F. A., Garibay, J. C. (20I3). Making a difference in science education: the impact of undergraduate research programs. American educational research journal, 50(4), 683-7I3.

Hensiek, S., DeKorver, B. K., Harwood, C. J., Fish, J., O’Shea, K., Towns, M. (20I6). Improving and assessing student hands-on laboratory skills through digital badging. Journal of Chemical Education, 93(I I), I847-1854. 
Hunter, A. B., Laursen, S. L., Seymour, E. (2007). Becoming a scientist:The role of undergraduate research in students' cognitive, personal, and professional development. Science education, 9 I (I), 36-74.

Kerr, D., Ratcliff, J., Tabb, L.,Walter, R. (2020). Undergraduate nursing student perceptions of directed self-guidance in a learning laboratory:An educational strategy to enhance confidence and workplace readiness. Nurse Education in Practice, 42, 102669.

Kinkel, D. H., \& Henke, S. E. (2006). Impact of Undergraduate Research on Academic Performance, Educational Planning, and Career Development. Journal of Natural Resources and Life Sciences Education, 35( I), I94-20I

Lopatto, D. (2003). The essential features of undergraduate research. Council of Undergraduate Research Quarterly. 24. I39- 142.

Lopatto, D. (2007). Undergraduate research experiences support science career decisions and active learning. CBE Life Sci Educ, 6(4), 297-306.

Mabrouk, P. A., \& Peters, K. (2000). Student perspectives on undergraduate research (UR) experiences in chemistry and biology. CUR Quarterly, 2 I (I), 25-33.

Novak, G., Patterson, E.T., Gavrin, A., Wolfgang, C. (1999). JustIn-Time teaching: Blending active learning with web technology. Prentice Hall, N.J.

Pace, C. R. (1985). The credibility of student self-reports.

Paul, J., Jefferson, F. (2019). A Comparative analysis of student performance in an online vs. face-to-face environmental science course from 2009 to 2016 . Frontiers in Computer Science, I(7).

Porter, S. R. (20I3). Self-reported learning gains:A theory and test of college student survey response. Research in Higher Education, 54(2), 201-226.

Rech, D., \& Mortimore, J. (2020). From soup to nuts: Expanding liaison and technical services for OER development. International Journal of Open Educational Resources, 2(I).

Rodenbusch, S. E., Hernandez, P. R., Simmons, S. L., Dolan, E. L. (2016). Early engagement in course-based research increases graduation rates and completion of science, engineering, and mathematics degrees. CBE-Life Sciences Education, 15(2), ar20.
Schneider, K. R., Kuperman,A.,Watts,A., Barulich, D., Campbell, T. (202I). Tracking and assessing undergraduate research campus-wide: Demographics, academic success, and post-graduation plans. Journal of the Scholarship of Teaching and Learning, 2 I (I).

Sens, D. A., Cisek, K. L., Conway, P., Doze,V. A. (20I7). An IDeA for enhancing undergraduate research at rural primarily undergraduate institutions. Advances in physiology education, $4 I(3), 464-47 I$.

Serafin, J. M., \& Chabra, J. (2020). Using a cooperative handson general chemistry laboratory framework for a virtual general chemistry laboratory. Journal of Chemical Education, 97 (9), 3007-3010.

Stanford, J. S., Rocheleau, S. E., Smith, K. P.W., Mohan, J. (2017). Early undergraduate research experiences lead to similar learning gains for STEM and Non-STEM undergraduates. Studies in Higher Education, 42(I), I I5-I29.

Tootle, T. L., Hoffmann, D. S., Allen, A. K. (20I9). Spracklen, A. J.; Groen, C. M.; Kelpsch, D. J., Mini-Course-Based undergraduate research experience. Journal of College Science Teaching, 48(6), 44-54.

Unal, S. (2008) Changing students' misconceptions of floating and sinking using hands-on activities. Journal of Baltic Science Education, 7 (3), I34- I 46.

The University of Texas at Austin College of Natural Sciences. (2019). Freshmen Research Initiative. https://cns.utexas.edu/ fri

Weston, T. J., \& Laursen, S. L. (20I5). The undergraduate research student self-assessment (URSSA):Validation for use in program evaluation. CBE-Life Sciences Education, I4(3), ar33.

Wladis, C., Conway, K. M., Hachey, A. C. (20I5). The Online STEM classroom-who succeeds? An exploration of the impact of ethnicity, gender, and non-traditional student characteristics in the community college context. Community College Review, 43(2), I42-164 